\section{AB0575 \\ THE EFFECT OF METABOLIC SYNDROME ON CARDIOVASCULAR DISEASE AND CUMULATIVE ORGAN DAMAGE IN TAKAYASU'S ARTERITIS}

Nilüfer Alpay Kanıtez ${ }^{1}$, Sema Kaymaz Tahra ${ }^{2}$, Ayten Yazici ${ }^{3}$, Ayse Cefle ${ }^{3}$, Mete Kara ${ }^{4}$, Handan Yarkan-Tuğsal ${ }^{5}$, Önay Gerçik ${ }^{6}$, Servet Akar ${ }^{6}$, Fatos Onen ${ }^{5}$, Kenan Aksu', Gökhan Keser ${ }^{4}$, Cemal Bes ${ }^{7}$, Sevil Kamalı ${ }^{8}$, Fatma Alibaz-Oner ${ }^{2}$, Haner Direskeneli ${ }^{2} .{ }^{1} \mathrm{Koc}$ University School of Medicine, Rheumatology, Istanbul, Turkey, ${ }^{2}$ Marmara University, School of Medicine, Rheumatology, Istanbul, Turkey; ${ }^{3}$ Kocaeli University School of Medicine, Rheumatology, Kocaeli, Turkey; ${ }^{4}$ Ege University, School of Medicine, Rheumatology, Izmir, Turkey, ${ }^{5}$ Dokuz Eylül University School of Medicine, Rheumatology, izmir, Turkey; ${ }^{6}$ Izmir Katip Celebi University, School of Medicine, Rheumatology, Izmir, Turkey, ${ }^{7}$ University of Health Sciences, Bakırköy Sadi Konuk Research and Training Hospital, Rheumatology, Istanbul, Turkey, ${ }^{8}$ Private Office, İstanbul, Turkey

Background: As a result of arterial ischemia, the frequencies of hypertension $(\mathrm{HT})$, ischemic heart disease, congestive heart failure and atherosclerosis have been shown to increase and contribute to mortality in patients with Takayasu's arteritis (TAK). Determining cardiovascular disease (CVD) and associated risk factors in TAK is important for a comprehensive treatment approach and better disease prognosis. Data about the effect of metabolic syndrome (MetS) which is known as a risk factor for CVD on TAK are limited.

Objectives: The aim of this study was to determine the prevalence of MetS in patients with TAK and its effect on CVD and cumulative organ damage. Methods: A total of 122 TAK patients, followed by Turkish Takayasu Study Group in 7 tertiary Centers and diagnosed according to the 1990 ACR criteria were consecutively assessed for cumulative organ damage (VDI score), history of CVD and MetS as defined by the National Cholesterol Educational Program Adult Treatment Panel III (NCEP ATP III). CVD was defined as coronary artery disease or cerebrovascular event (myocardial infarction or stroke).

Results: Eighty-seven percent of patients were female and the median age was $39(17-65)$ years. The frequency of MetS was $14.7 \%$ and CVD was $13.1 \%$. The median age, disease duration, smoking prevalence and CVD were found slightly higher in MetS group, without reaching statistical significance. There were no differences in VDI score between the groups (Table 1).

Table 1. Cardiovascular disease (CVD) and cumulative organ damage distributions according to the presence of MetS in patients with Takayasu's arteritis

\begin{tabular}{lccc}
\hline & MetS+TAK n: 18 & MetS-TAK n: 104 & p values \\
\hline Age (median, min-max) & $44(27-63)$ & $37(18-65)$ & 0.056 \\
Disease duration (year, mean \pm SD) & $11.7 \pm 9.2$ & $10.0 \pm 9.3$ & 0.535 \\
Female n (\%) & $17(94)$ & $89(86)$ & 0.273 \\
Smoker n (\%) & $3(17)$ & $10(10)$ & 0.583 \\
CVD n (\%) & $4(22)$ & $12(16)$ & 0.202 \\
Cumulative GC(g, mean $\pm S D)$ & $9.8 \pm 6.1$ & $10.1 \pm 9.1$ & 0.872 \\
NIH-Aktive n (\%) & $3(17)$ & $13(13)$ & 0.462 \\
VDI (mean $\pm S D)$ & $4.1 \pm 2.6$ & $4.2 \pm 2.6$ & 0.941 \\
\hline
\end{tabular}

(TAK: Takayasu's arteritis, MetS: Metabolik sendrom, SD: Standart deviation, GC:

Glucocorticoids, NIH: "National Institutes of Health", VDI: "Vasculitis damage index")

Conclusion: MetS frequency in our TAK patients was observed to be less than the normal population data obtained from METSAR (Turkish MetS study in normal population) in Turkey (female: $39.6 \%$, male: $28 \%$ ). The discrepancy with SLE, which is another inflammatory autoimmune disease having a higher frequency of MetS related with organ damage, may be explained with the potentially more severe disease course in SLE patients requiring higher cumulative doses of glucocorticoids (1).

\section{REFERENCE}

[1] Demir S, Artim-Esen B, Şahinkaya Y, Pehlivan Ö, Alpay-Kanıtez N, Omma A, et al. Metabolic syndrome is not only a risk factor for cardiovascular diseases in systemic lupus erythematosus but is also associated with cumulative organ damage: a cross-sectional analysis of 311 patients. Lupus. 2016;25:177-84
Disclosure of Interests: Nilüfer Alpay Kanitez: None declared, Sema Kaymaz Tahra: None declared, Ayten Yazici: None declared, Ayse Cefle: None declared, Mete Kara: None declared, Handan Yarkan-Tuğsal: None declared, Önay Gerçik: None declared, Servet Akar Grant/research support from: MSD, Abbvie, Roche, UCB, Novartis, Pfizer, Amgen, Consultant for: MSD, Abbvie, Roche, UCB, Novartis, Pfizer, Amgen, Speakers bureau: Pfizer, Fatos Onen: None declared, Kenan Aksu: None declared, Gökhan Keser: None declared, Cemal Bes: None declared, Sevil Kamalı: None declared, Fatma Alibaz-Oner: None declared, Haner Direskeneli: None declared

DOI: 10.1136/annrheumdis-2019-eular.4055

\section{AB0576 \\ SERUM CATHELICIDIN (LL 37) LEVELS IN PATIENTS WITH BEHCET'S DISEASE AND ITS ASSOCIATION WITH DISEASE ACTIVITY}

Melike Zelal Cakir ${ }^{1}$, Pelin Oktayoglu ${ }^{1}$, Nuriye Mete ${ }^{2}$, Mehmet Caglayan ${ }^{1,1} .{ }^{1}$ Dicle University Faculty of Medicine, Department of Physical Medicine and Rehabilitation, Division of Rheumatology, Diyarbakir, Turkey, ${ }^{2}$ Dicle University Faculty of Medicine, Department of Biochemistry, Diyarbakir, Turkey

Background: Behcet's disease (BD) is a recurrent multisystem inflammatory disease which is characterized by recurrent episodes of oral aphthous and genital ulcers, ocular inflammation and skin lesions. Antimicrobial peptides (AMPs) such as the cathelicidin (LL-37) and defensins have recently been implicated in the pathogenesis of autoimmune and autoinflammatory diseases.

Objectives: The aim of this study was to investigate the serum levels of cathelicidin and its potential association with disease activity, and some other laboratory parameters such as erythrocyte sedimentation rate (ESR) and Creactive protein (CRP), white blood cell count (WBC) in patients with $B D$. Methods: A total of 45 patients who presented to Dicle University Rheumatology clinics between September 2018 and December 2018 and met the International Study Group Classification Criteria for BD and 37 healthy control subjects who presented to Dicle University Physical Medicine and Rehabilitation clinics for various reasons other than rheumatoid complaints between the same dates were included in this study. Patients' demographic features, including age and sex, were noted. Duration of disease was also noted, and the disease activity was assessed by means of BD Current Activity Form (BDCAF). Laboratory investigations included erythrocyte sedimentation rate (ESR), C-reactive protein (CRP), complete blood count and routine biochemical analyses. Serum levels of cathelicidin (LL 37) were determined by means of human cathelicidin antimicrobial peptide ELISA Kit according to the manufacturer's protocol.

Results: Serum mean level of cathelicidin (LL 37) in patients with BD was lower than healthy controls but this result was not statistically significant. Cathelicidin levels were not correlated with ESR, CRP, BDCAF and WBC $(p>0.05)$

Conclusion: However serum mean levels of cathelicidin (LL 37) were lower in patients with BD compared to healthy controls, this result was not statistically significant. It may may be sourced from our relatively small sample size. To validate cathelicidin (LL 37) value as a prognostic or pathophysiologic biomarker, future studies should investigate the levels of cathelicidin LL37 in patients with BD in large cohorts of patients with different levels of disease activity, remission, and relapse.

\section{REFERENCE}

[1] Hoffmann MH, Bruns H, Backdahl L, et al. The cathelicidins LL-37 and rCRAMP are associated with pathogenic events of arthritis in humans and rats. Ann Rheum Dis. 2013;72(7):1239-48

[2] Gasim A. Cathelicidin antimicrobial peptide as a serologic marker and potential pathogenic factor in antineutrophil cytoplasmic antibody-associated vasculitis. Arthritis Res Ther. 2014: 28;16(1):105

Disclosure of Interests: None declared DOI: 10.1136/annrheumdis-2019-eular.6146 